NASA Technical Memorandum 86803

5.

\title{
Dynamics and Controls Flight Testing of the X-29A Airplane
}

Joseph Gera

January 1986

NASA-TM-86803

19860009842

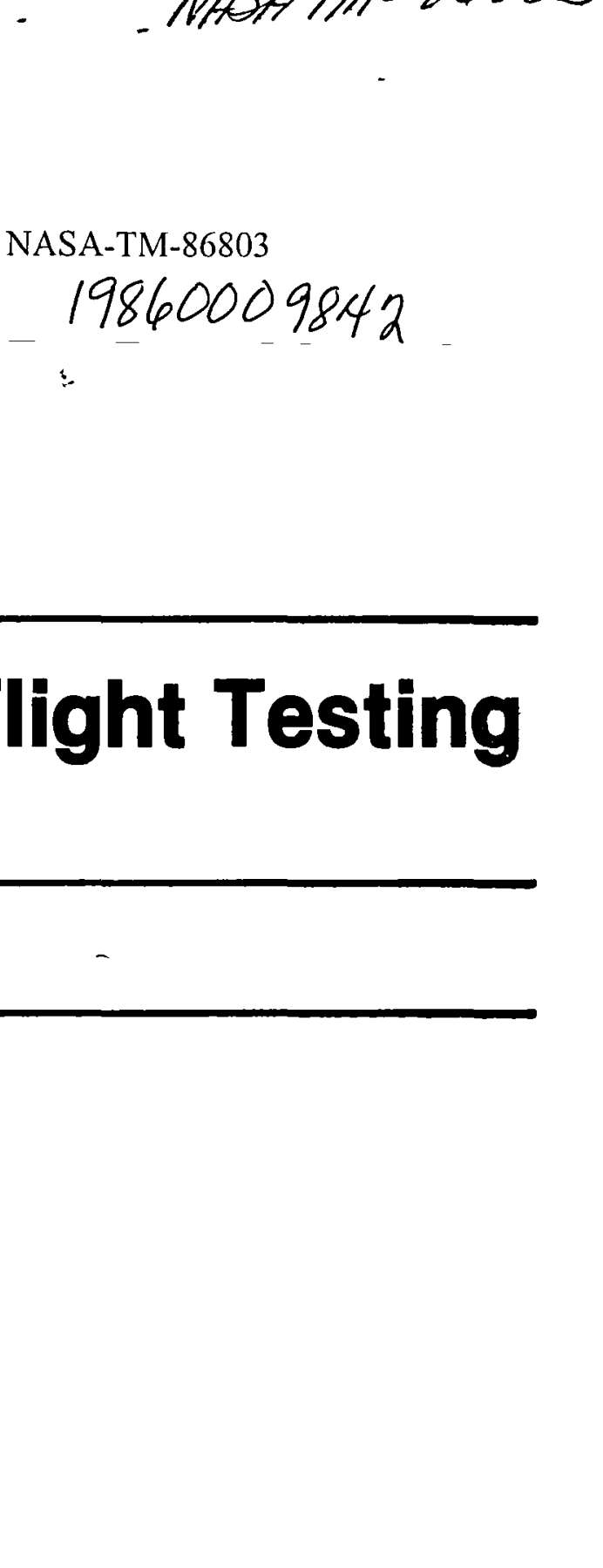

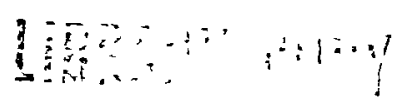

FEis ! : N

LARGLE, ,

besis:

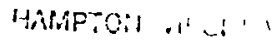


NASA Technical Memorandum 86803

\section{Dynamics and Controls Flight Testing of the X-29A Airplane}

Joseph Gera

Ames Research Center, Dryden Flight Research Facılity, Edwards, Calıfornia

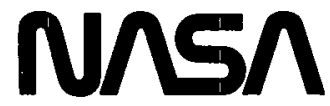

Natıonal Aeronautics and

Space Admınıstratıon

Ames Research Center

Dryden Flıght Research Facility

Edwards, Calıfornıa 93523 
period response control that are now reaching the testing stage are not shown in the schematic.

A block diagram of the automatic camber control is shown in Fig. 4. As shown, the optimum value of the canard position is contained in a table as a function of altitude, Mach number, and angle of attack. Similarly, the optimum strake flap position is in another table as a function of altitude, Mach number, and symmetric flap deflection. Consequently, the final trimming at any flight condition is accomplished by symmetric flap deflection that has a trim value that uniquely fixes the other two types of surfaces - the canards and strake flaps. One feature of this system shown in Fig. 4 is that, in the event of symmetric flap saturation, the strake flaps w111 accomplish the final trimming.

\section{Lateral-Directional Control Laws}

Although not shown in detall in Fig. 5 , the lateral-directional control system is relatively conventional. It consists of the usual roll and yaw damper, as well as a turn coordinating feature that uses lateral acceleration feedback and a farriy elaborate roll-yaw interconnect. A forwardloop integrator in the roll channel provides for an automatic lateral trim function in the up-andaway configuration. As in the pitch axis, gains are scheduled as functions of air data and angle of attack. In the present version of the control laws, the conventional yaw damper is replaced by an equivalent sideslip rate feedback system that uses the pitch and roll attitude signals from the attitude and heading reference system.

This brief description of the flight control system cannot give a complete account of the evolution, design methodology, and criteria of the system. During most of the $X-29 A$ development cycle, the design of the control system was regarded as the most critical area of technology. Consequently, the amount of analysis, simulation, and testing - by both the contractor and an independent government team - exceeded those of other similar programs. It was fortunate that many members of both teams remained with the airplane for the flight tests and provided their experience for a safe and efficient envelope expansion program.

\section{Special Considerations}

A primary consideration in flight test was the amount of static and dynamic instability of the basic $X-29 A$ airframe. Previous experience with statically unstable vehicles included the highiy maneuverable aircraft technology (HiMAT) and the advanced fighter technology integration (AFTI) F-16. However, these alrcraft had only modest amounts of negative static margins, -5 and -8 percent, respectively. In comparison with these aircraft, the $X-29 A$ with its nearly 40 -percent negative static margin and a timeto-double-amplitude of $140 \mathrm{msec}$ at the maximum dynamic pressure seemed like a reversed weather vane during the preparation for the first fiıgt.

Although many hours of simulation were logged by the X-29A pilots and engineers, some uncertainties remained unanswered until the forst flight. The author believes that these uncertainties included the exact sequence of events during ground-to-air and air-to-ground transitions. In the $X-29 A$ control laws, significant changes with implications on flight safety - occur during these transitions. The $X-29 A$ simulations at Grumman and NASA included a ground plane, landing gear dynamics, and models of multiple contact weighton-wheel switches on each gear. Nevertheless, the ability to simulate the exact sequence of events during transitions was always open to question.

Another issue that is not fully answered at present involves actuator hysteresis. The unstable $X-29 A$ is being flown without any effective stability augmentation inside the hysteresis band, a factor that allows the possibility of at least a limit cycle in the pitch axis.

Another concern was the ability of the wing to function properly in an unsteady flow field created by the canards. Vigorous canard motions observed during varrous ground and taxi tests did not allay this concern.

Two factors were significant in approaching the flight tests of the $X-29 A$ airplane with some measure of confidence. (1) the test team consisted of a closely integrated group of engineers with experience in several disciplinary areaso and (2) a high-fidelity simulator dedicated to flight test preparation and support provided answers to many concerns. However, as these answers were not universally accepted before flying the airplane (to paraphrase the late Hugh L. Dryden) it was ultimately the flight testing that separated the real from the 1 magined problems and uncovered what had been overlooked or unexpected.

\section{Flight Test Approach}

The challenge posed by the relaxed static stability of the $x-29 A$ airplane was greater than that of other previously tested unstable airframes the H1MAT and the AFTI/F-16. The HIMAT alrcraft was an unmanned remotely piloted vehicle, in the AFTI/F-16, the airframe, actuators, and engineinlet installations had been in production for several years. For this reason, the X-29A flight tests relied on simulation and control system analysis on a day-to-day basis to a greater extent.

Although the Ames-Dryden X-29A simulator appears to be relatively simple, it has fullenvelope capability and includes a complete set of flight control computers and the associated fallure status and control panel (Fig. 6) in the cockpit. During its development, the simulator was carefully validated several times against a much more complex simulation - the Grumman hybrid simulation and system integration test bench. The validation consisted of time history overplots at several firght conditions in each mode and each axis. The predicted agreement between the two simulations is shown in Fig. 7.

It 15 important to note that the Ames-Dryden simulation was required to reproduce nonlinearities resulting from position and rate saturation of one or more control surfaces. Among the many useful features of the Ames-Dryden simulation are its flexibility to accommodate changes and ease of operation. In addition, it has been avallable for flight support in three, functionally identical 
versions (1) real-time, piloted version incorporating the triplex flight control computers and fallure status and control panel, (2) same as (1), but in an all-FORTRAN version, and (3) same as (2), but not operating in real time. Instead of the cockpit interface, this simulation is driven by an external data file, for example, flight data consisting of pilot control positions. All three versions of the simulation are under rigorous configuration control and are subject to the same validation procedures.

The flight tests are also supported by extensive linear analysis capability that was developed by NASA earlier in preparation for the independent control system verification and validation process. During the flight test program, the following features of this computer-based, highly interactive inear analysis have been in use on a flight-byflight basis (1) multiple-surface trimmer and I inear system generator, (2) stability analysis in the time and frequency domain, and (3) handing qualities prediction based on the lower order equivalent system (MIL-F-8785C). 5

The above analysis made use of the linear models of the combined rigid airplane and digital flight control systen including actuator, sensor, and fuel system dynamics, structural and anti-aliasing filters, and a Páde approximation of the transport lag that results from the digital processing of the control laws. As an example, the longitudinal linear model of the rigid $x-29 A$ in the normal digital mode is a forty-eighth order system.

\section{Flight Test Results}

The first flight was preceded by 11 engine runs and 4 taxi tests, the latter with several high-speed runs in each pilot selectable control law mode. Most of these tests were monitored by a fully manned ground control center. Hence, as the ground tests were completed, the test range, on-board instrumentation, telemetry system, and real-time flight data processing were fully checked out.

The overall objective of the $X-29 A$ flight tests was the demonstration of the various technologies that were employed in the design. In the area of flight dynamics and control, the primary objective was to demonstrate the design goals for stability margins and handling qualities. To date, the $x-29 \mathrm{~A}$ has met or exceeded these goals. The airplane is well damped about each axis, and the control surfaces are quiet in flight. The numerical values of the stability margins are being determined successfully from frequency sweeps performed by the pilot. This procedure is facilitated by the fact that, despite the multiplicity of control surfaces and feedbacks, the longitudinal-axis feedback signals are summed into a single signal at one point.

As shown schematically in Fig. 8, the signals $X$ and $Y$ used as inputs to a fast Fourier transform algorithm specify completely the open-loop frequency response. This allows the monitoring of the overall system stability at each new flight condition. The signals $X$ and $Y$, as well as add $1-$ tional necessary signals, are telemetered to the ground during flight. Hence, it is technically feasible to determine both the open- and closedloop frequency responses immediately after the pilot has performed the frequency sweep in a given axis. To date, however, both procedures are completed after each flight. Frequency sweeps, performed in smooth air, yield gain and phase characteristics in the $0.5-$ to $30.0-\mathrm{rad} / \mathrm{sec}$ frequency range that are repeatable within a $\pm 1.5-\mathrm{dB}$ and $\pm 3-\mathrm{deg}$ band, respectively. At or above $30 \mathrm{rad} / \mathrm{sec}$, the validity of the data is questionable because of the attenuation of the pilot input signal across the command shaping. The flight data are not only repeatable, but they have also shown remarkably close agreement with analytical predictions in the same frequency range. At least in this frequency range, therefore, the relatively high order of i inear mathematical models appear to include all significant dynamics.

An example of the comparison of measured and predicted frequency responses is shown in Fig. 9. Comparison of the time histories in response to a longitudinal stick doublet at the same flight condition is shown in Fig. 10. It is interesting to note the effects of a 25-percent increase in the loop gain in the above example on both the openloop frequency response and the time histories. This would be equivalent to overpredicting each of the control effectiveness derivatives by 25 percent. As shown 1 F Figs. 9 and 10, the 25-percent difference is more obvious in the frequency domain. For this reason, the open-loop frequency response has become a very important flight test tool. In fact, the $X-29 A$ team found that, during the envelope expansion of the statically unstable airframe that uses multiple, interconnected control surfaces, the monitoring of the open-loop frequency response is the most reliable indication of overall stability. The reason for this is believed to be twofold. First, the flight estimation of critical aerodynamic derivatives, such as $\mathrm{C}_{\mathrm{m}_{\alpha}}$ or

the control effectiveness derivatives, has so far been less than successful. Second, the augmented a irplane response is not dominated by the aerodynamics of the airframe, but by the flight control system.

Flight safety is ensured by several additional measures. Each flight is preceded by several simulations of the complete mission from takeoff to touchdown. During these rehearsals, various subsystem fallures are simulated in order to test the fault reaction not only of the system, but also of the pilot and the control room personnel. In addition, these simulation sessions allow an efficient sequencing of the test points and provide reliable prediction of whether a particular flight test maneuver can be performed within the available performance levels.

Predicted trim values of angle of attack and of the three longitudinal control surfaces and surface rates constitute additional flight safety parameters. Experience to date has shown that predictions of the angles should be within $\pm 1.5 \mathrm{deg}$, and of the rates within $\pm 5 \mathrm{deg} / \mathrm{sec}$, of the actual values. To achieve these levels of agreement, it is necessary to trim and derive the linearized mathematical models at the exact flight condition, weight, and center of gravity of the upcoming test point. The ready avallability of both the analysis tools and the results of the final simulation session makes this possible. 
One of the ground rules of the current envelope clearance program is that unexpected $\mathrm{d}$ ifferences between filight data and prediction constitute sufficient reason to halt envelope expansion until the reasons for the differences are understood. With all these flight safety parameters at hand for each flight, the test team is reasonably confident that no surprises should occur close to the stabilized test points. To guard against unexpected handling qualities difficulties that might occur during an emergency when the pilot may be required to make largeamplitude, aggravated control inputs, one of the preflight simulation sessions is required to include such inputs while simultaneously varying significant aerodynamic derivatives.

Handling qualities tests to date have consisted of relatively benign, open-loop tasks such as pulses, doublets, attitude-angle captures, partial and full rudder sideslips, 360-deg rolls, some gunsight tracking, and formation flying. Quantitative results and pilot comments show that the $X-29 A$ will probably meet all the handling qualities design goals.

Control system problems have been minor and have required relatively simple software changes. Two of these problems were (1) insufficient roll trim authority - 4 percent of full stick - to correct an apparent right-wing heaviness cond1tion in the powered approach configuration, and (2) faulty flap saturation logic that prevented effective utilization of the automatic camber schedule in the event of saturated flaps during lateral-directional maneuvers.

Correlation of handing qualities predictions with flight results are being made in the longltudinal and lateral-directional axes. The frequency sweep data are used to compute the closedloop frequency response in a manner similar to the open-loop frequency response computation. Figures 11 to 13 show the steps involved from the frequency sweep to the generation of the lower order equivalent system. From the latter, the equivalent short-period modal response characteristics and the equivalent time delay are obtained. The linear mathematical models of the airplane are also approximated by the same low-order equivalent system. This allows direct comparison of the flight data with predicted results. The agreement has been generally close in all axes and control system modes. However, the equivalent system models have been somewhat short of the level 1 specification 5 because of the large equivalent time delays (in excess of $200 \mathrm{msec}$ ) yielded by the lower order transfer function fit procedure. To date, none of the $X-29 A$ prlots commented on perceptible time delays even during the close formation flying tasks. The question of whether the stick force feel system should be universally included in the derivation of the equivalent system has become the subject of a separate study at Ames-Dryden.

Other handing qualities parameters of the $X-29 A$ - such as modal frequencies, damping ratios, stick force per $g$, and time-to-roll $90 \mathrm{deg}$ - have been found typical, but not yet optimal, of fighter class airplanes. In the approach configuration, the apparent dihedral effect is slightly negative, that is, in rudder induced sideslips, the pilot must apply small lateral stick inputs in the direction of the rudder pedal deflection in order to keep the wings level. This effect is weak and does not restrict the crosswind landing 11 mits of the airplane.

In up-and-away flight, speed stability is neutral or even slightiy negative. This can be controlled by engaging the speed stability feature. However, speed stability is not preferred or desired by all of the pilots, even during the landing approach. The lack of noticeable stick force variation with airspeed (that is, self-trimming) appears to be a major factor in the excellent pilot ratings that the $X-29 A$ is given for handling in the landing pattern. Pilot comments indicate that the timing of the landing flare initiation is somewhat critical. Too high a flare results in excessive floating that may require repeated application of forward stick pulses - a factor that is undesirable to most $X-29 A$ pilots.

Operational experience, with the flight control system as well as with the entire X-29A a)rplane, has been outstanding. Up to flight 19 , in-flight fallures have been inconsequential and did not result in a flight control system downmode or an abort. It $1 \mathrm{~s}$ important to note, however, that the more critical regions of the $X-29 A$ flight envelope are still to be explored.

\section{Concluding Remarks}

Although at present the $X-29 A$ flight test program is only in its initial phases, the joint NASA, U.S. Alr Force Flight Test Center, and Grumman test team developed techniques and procedures that hold promise for continued successful testing while demonstrating the potential of the technologies incorporated in the test airplane. The subject of this paper is the flight test experience with the $x-29 A$ in the areas of flight controls and handling qualities.

In order to proceed safely with the flight tests, linear analysis and piloted simulation are integrated to a great extent into each flight. Analysis and simulation are used to generate a number of parameters that are important to flight safety. In addition to monitoring the usual flight test parameters, flight safety is enhanced by obtaining for each trim point before the flight the angle of attack and each surface position at the planned flight condition and airplane werght. For each maneuver, extreme values of each significant parameter are noted during preflight simulation so that a comparison of predictions with flight data is possible during each flight.

The open-loop frequency response of the $X-29 \mathrm{~A}$ is determined at each new flight condition by using fast Fourier transform techniques and pilotgenerated frequency sweeps. Gain and phase margin can be closely monitored and compared with predictions. Closed-loop frequency response, determined by similar techniques, is used to generate lower order equivalent systems to evaluate handling qualities and complement pilot ratings. Doublets, windup turns, and attitude-angle captures are compared with simulator time histories that are 
generated at the actual flight conditions and weight, as well as by the pilot inputs recorded in flight. As preparation for, unexpected handling qualities problems during emergencies, one of the preflight simulation sessions includes largeamplitude, aggravated pilot inputs while the significant stability derivatives are varied.

Experrence with the $X-29 A$ to date shows that the extremely relaxed static stability need not compromise flight safety; in fact, the envelope clearance has progressed according to plan without any control system discrepancies or unusual events. No inflight aborts, control system downmodes, or sensor fallures have been experienced. Stability margins have been close to design goals, gain and phase margins determined from flight data are found to be within $\pm 1.5 \mathrm{~dB}$ and $\pm 3 \mathrm{deg}$, respectively, of the predicted values. It appears that the use of multiple control surfaces for controlling the short-period response and minimizing the drag has been successful.

The $X-29 A$ is well-damped longrtudinally and lateral-directionally, and all control surfaces are quiet in flight. Pllot comments indicate that the airplane is likely to meet the handling qualities design goals without major control system modifications. To date, only two minor software changes affecting the handling qualities have been made. The first of these increased the roll trim authority, and the second corrected a minor fault in the flap saturation logic. The pilots find the a)rplane easy to handle in the traffic pattern, during the flare, and touchdown. However, the pilots object to the forward stick inputs that are required to suppress a tendency to float whenever the landing flare is initiated by the pilot a little too early. This tendency is common to pitch-rate command, attitude hold systems similar to the $X-29 A$. Therefore, the airplane can serve as a good testbed to find answers to the landing problems associated with these systems.

In summary, the flight test program has progressed very well, and during its first 7 months of flight testing, the X-29A airplane has successfully demonstrated several of its design goals

\section{References}

1Krone, N.J., Jr., "Divergence El imination with Advanced Composites," AIAA Paper 75-1009, Aug. 1975.

2Krone, N.J., Jr., "Forward-Swept-Wing Flight Demonstrator," AIAA Paper 80-1882, Aug. 1980.

3spacht, G., "The Forward-Swept Wing A Unique Design Challenge," AIAA Paper 80-1885, Aug. 1980.

${ }^{4}$ Whitaker, A., and Chin, J., "X-29 Digital Flight Control System Design," AGARD-CP-384, Active Control Systems - Review, Evaluation, and Projections, Oct. 1984.

5"Military Specification - Flying Qualities of Plloted Airplanes," MIL-F-8785C, Nov. 1980.
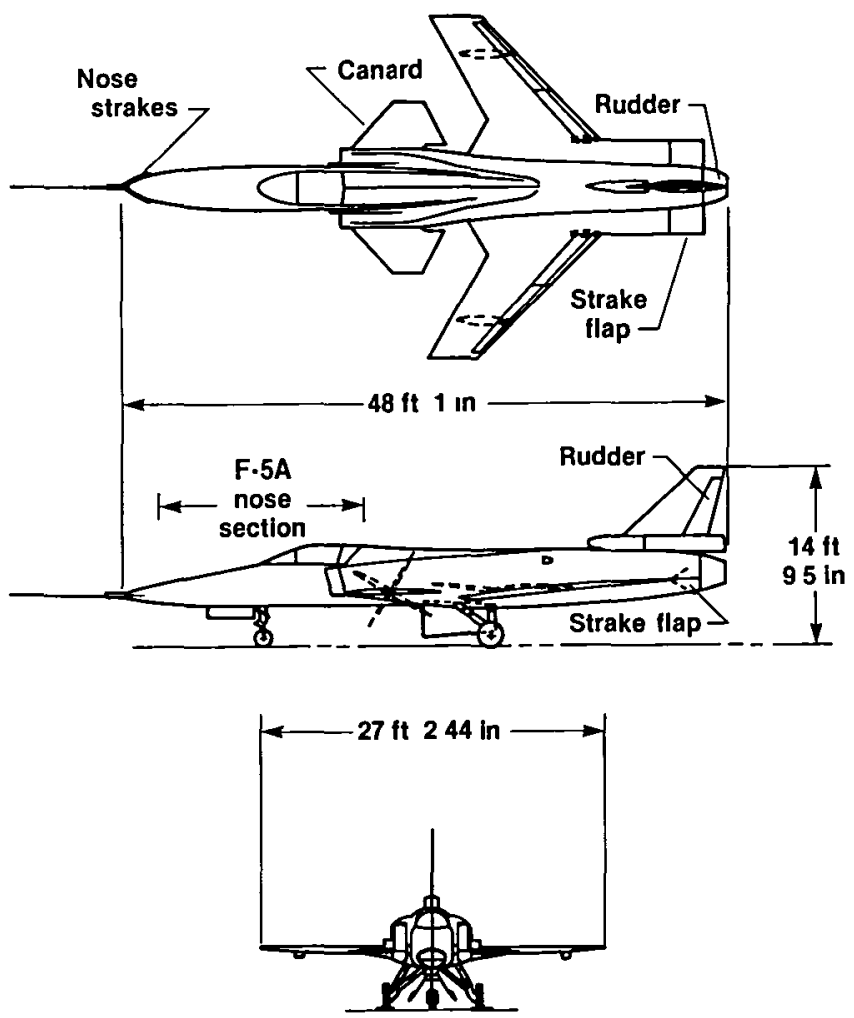

Frg. 1 X-29A airplane. 


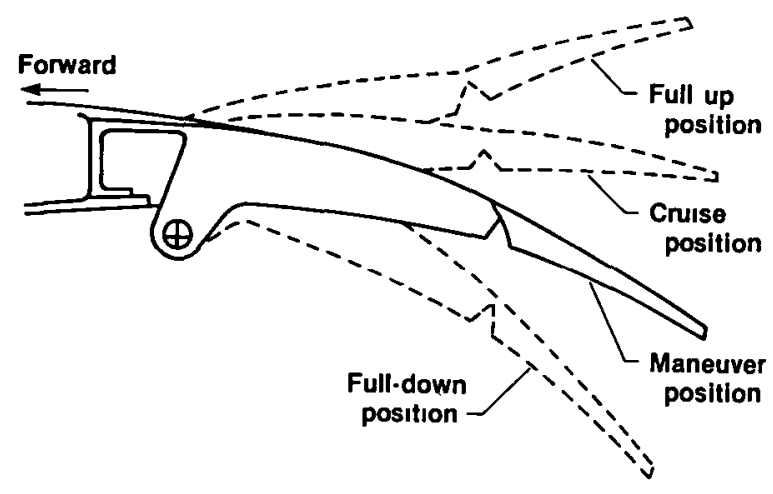

Fig. 2 X-29A full-span flap geometry.

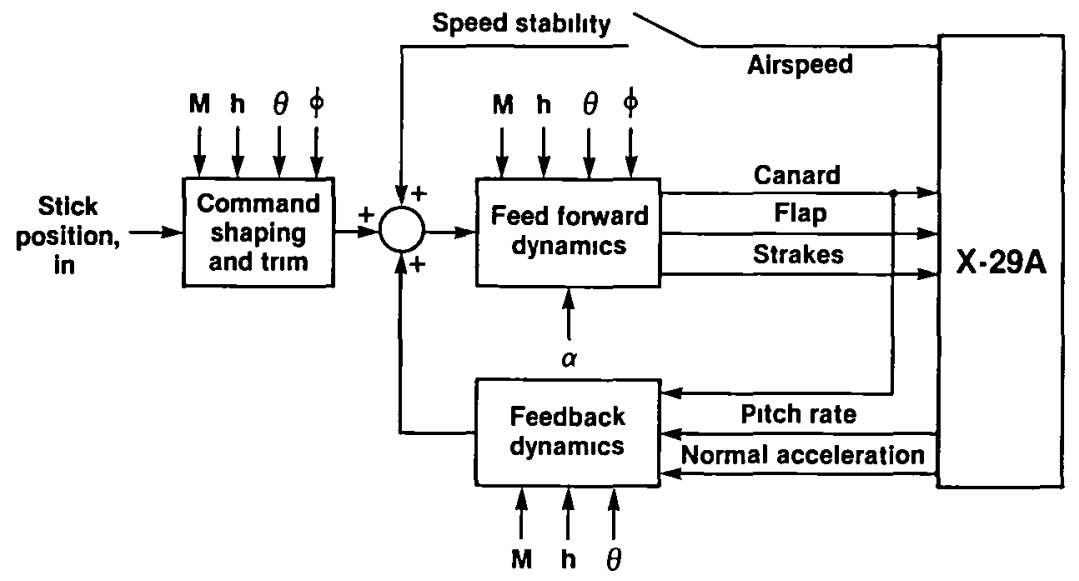

Fig. 3 Simplufied short-period response control, pitch axis.

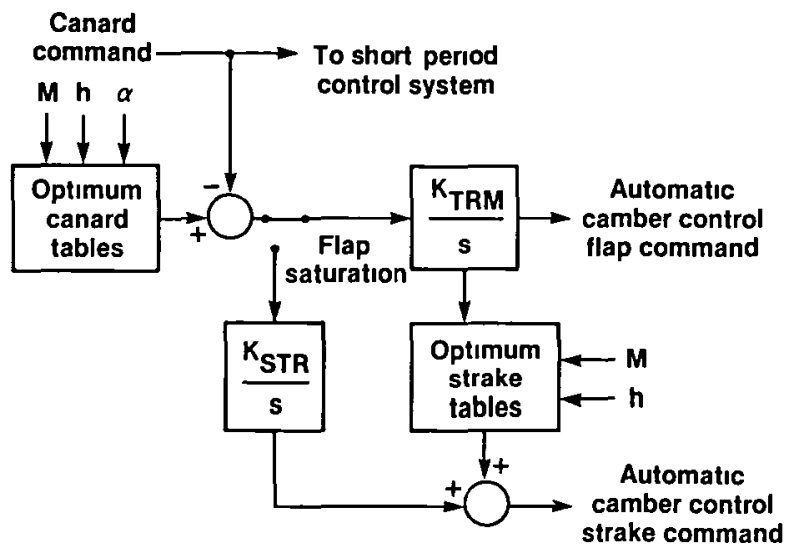

Fig. 4 Simplified long-period response, automatic camber control. 


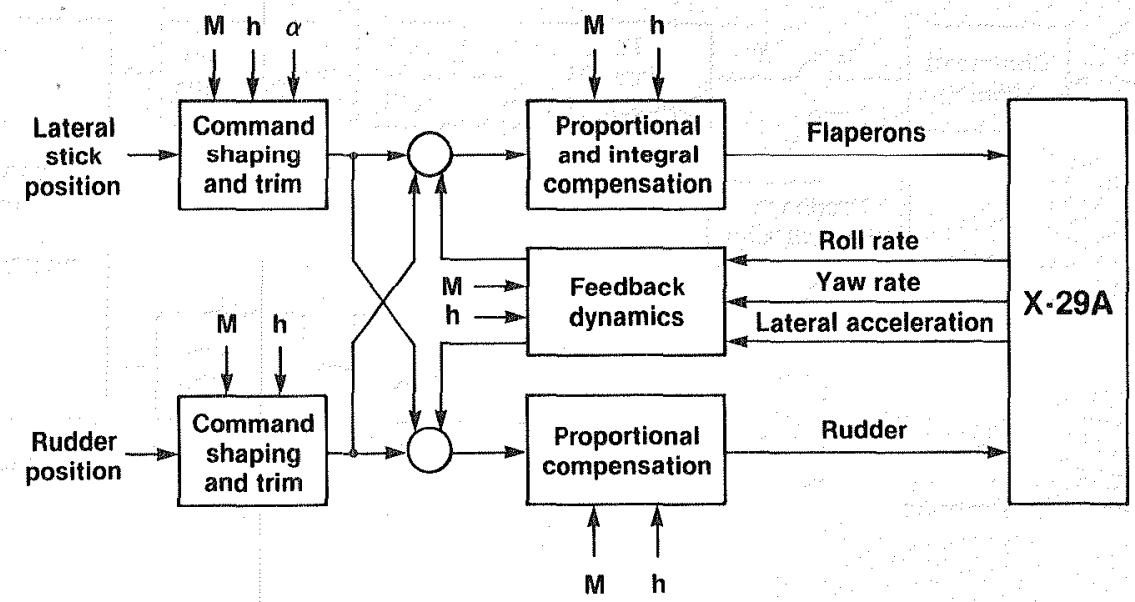

Fig. 5 Simplified lateral-directional control laws.

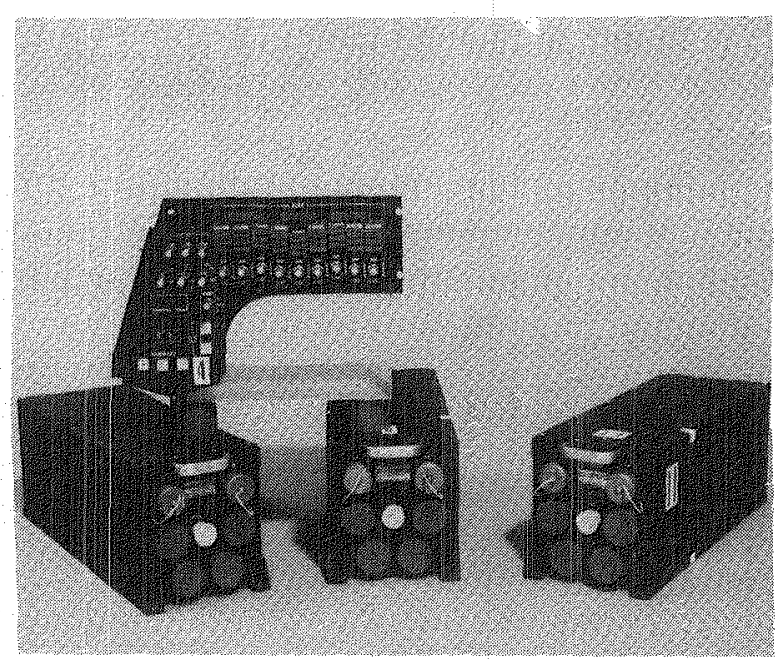

ECN 33239-300

Fig. 6 Flight control computers and failure status and control panel.
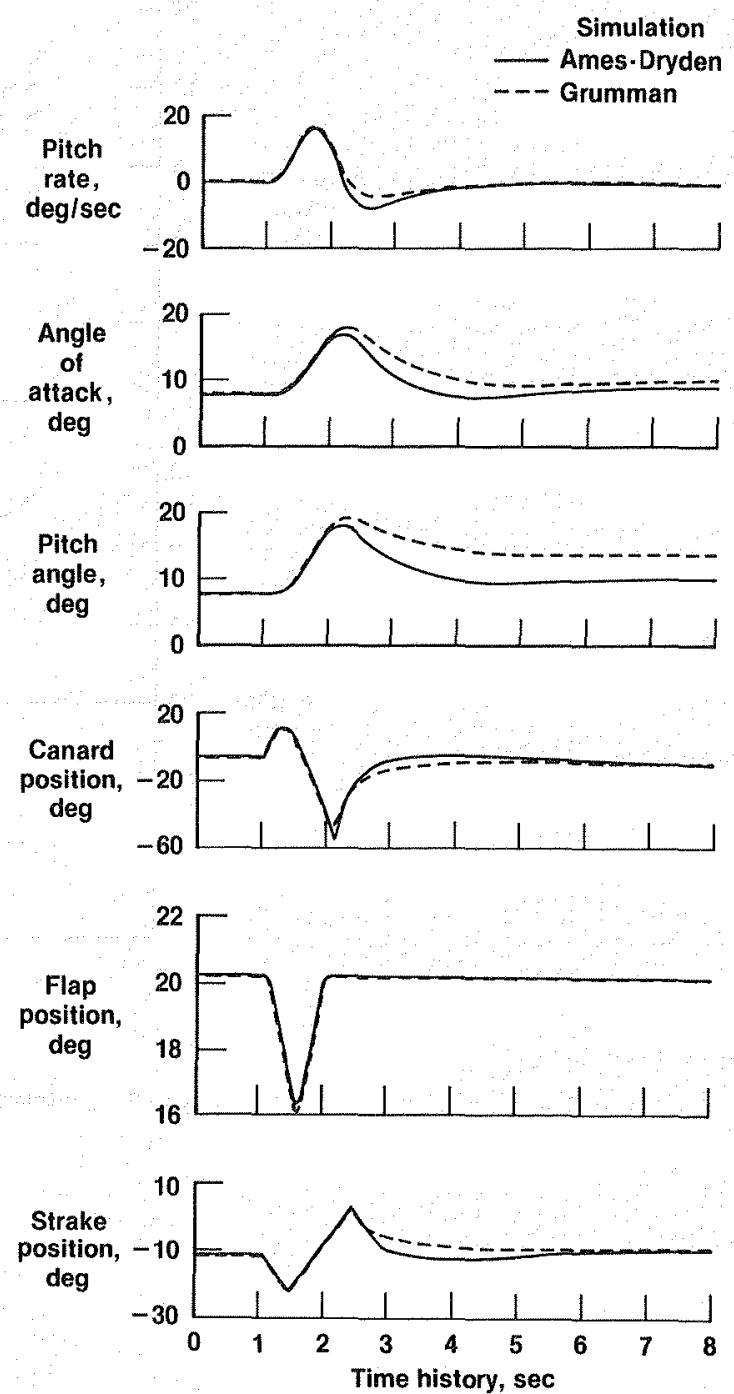

Fig. 7 similator validation comparison using large-amplitude control input. 


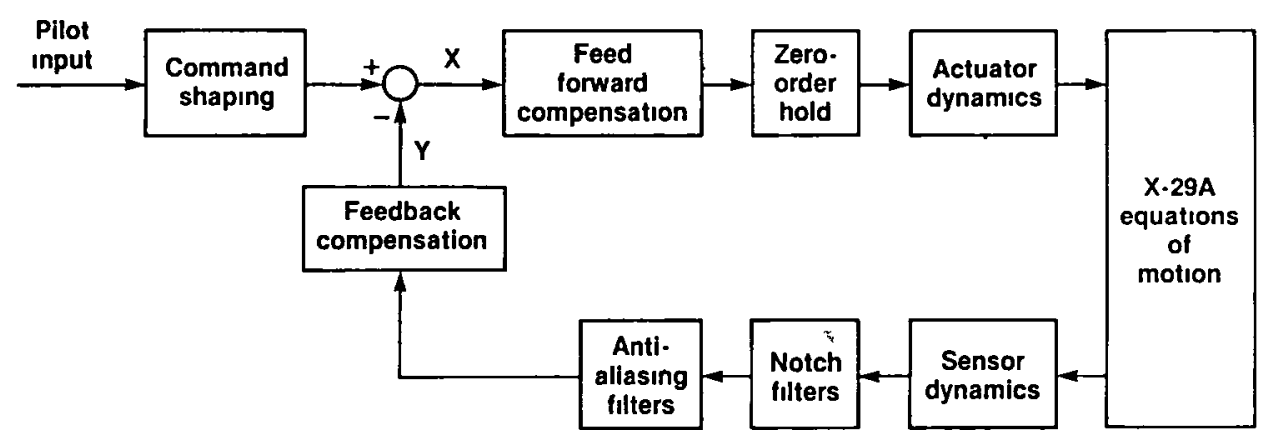

Fig. 8 Determination of open-loop frequency response input data from closedloop measurements.

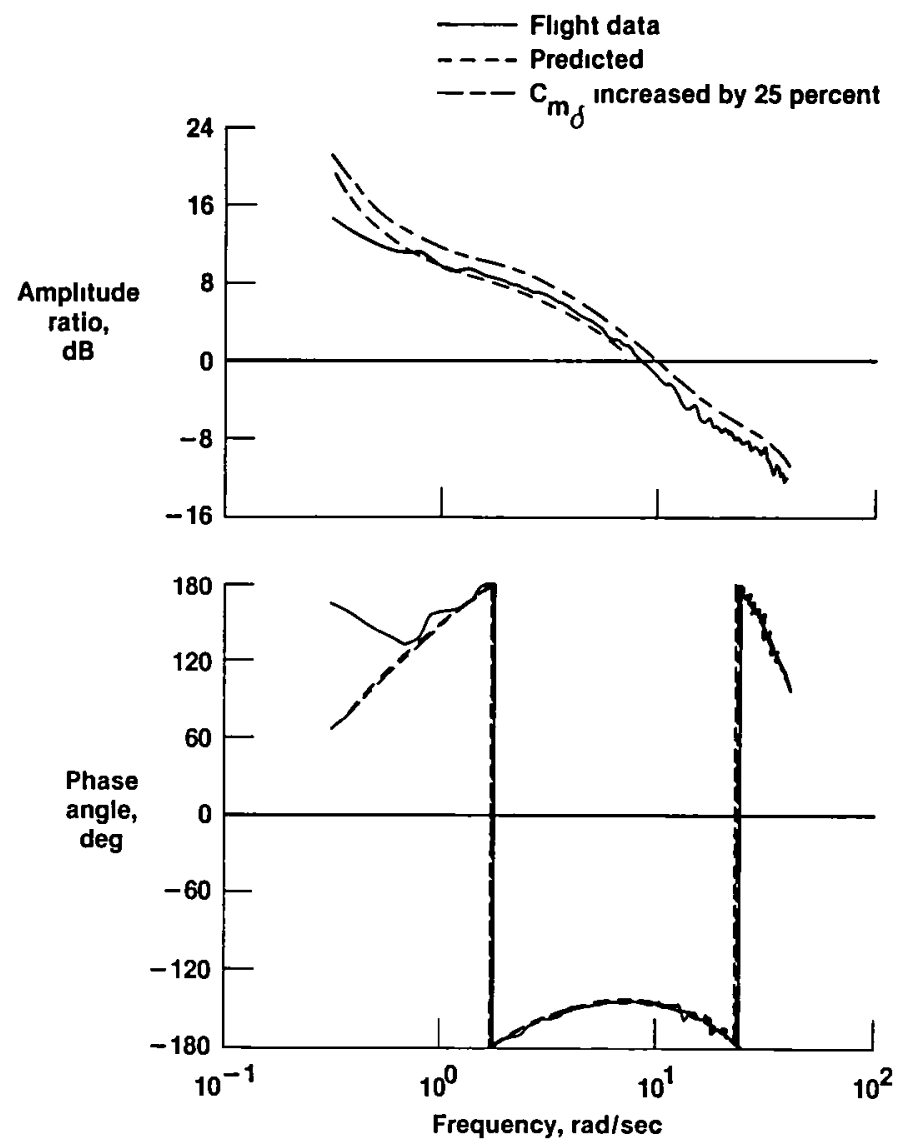

Fig. 9 Frequency response comparzon. 

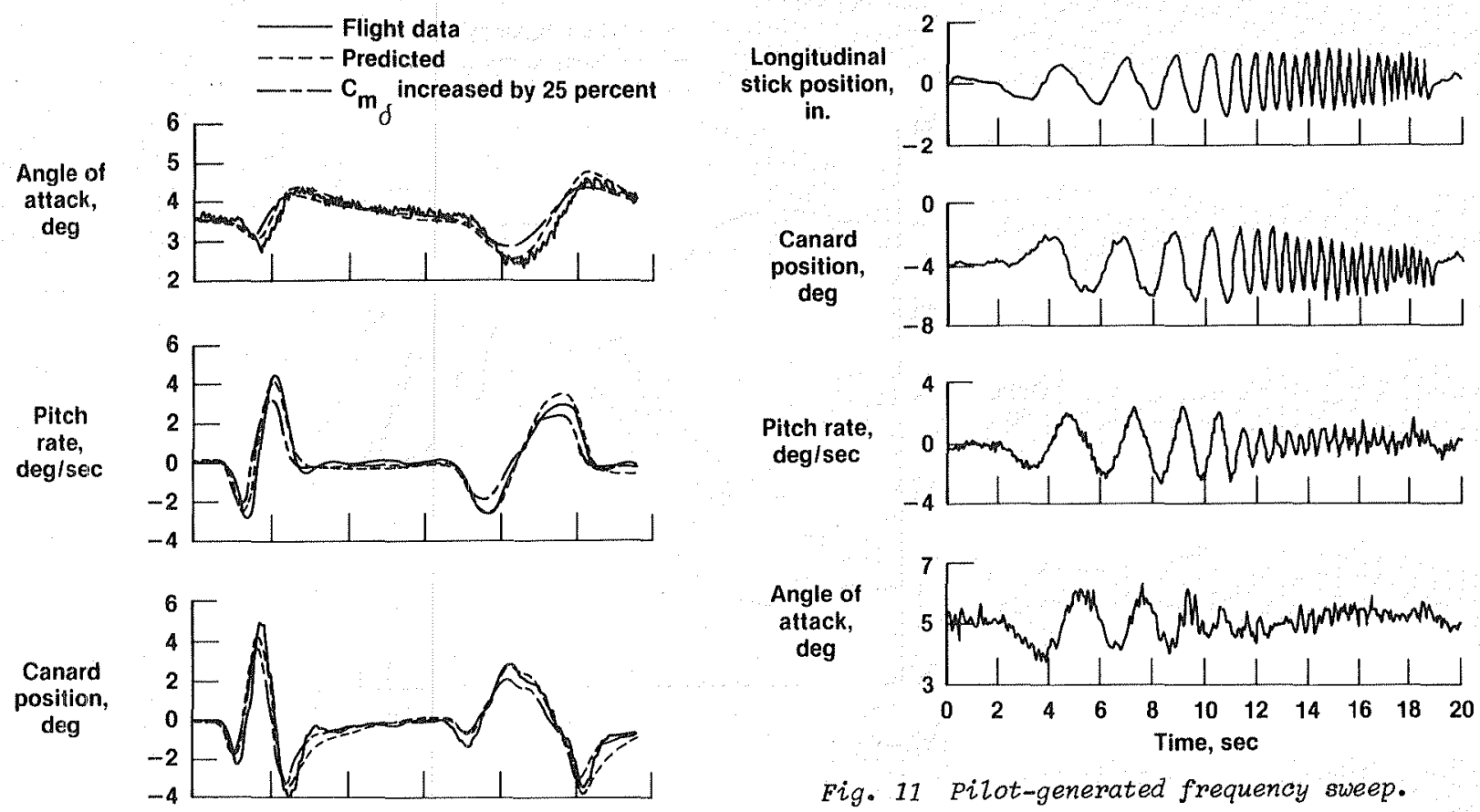

Fig. 11 Pilot-generated frequency sweep.

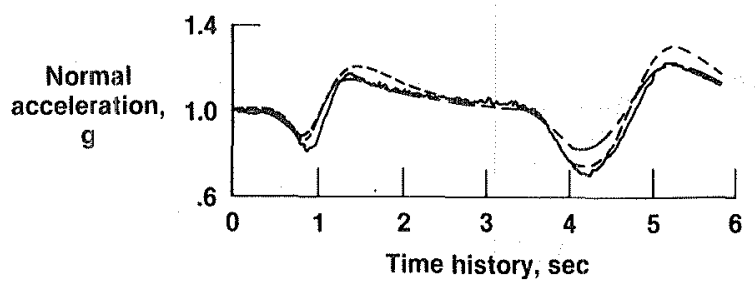

Fig. 10 Time history comparison.

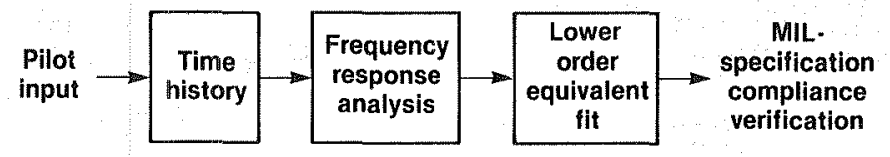

Fig. 12 Data processing sequence for closed-loop frequency response. 

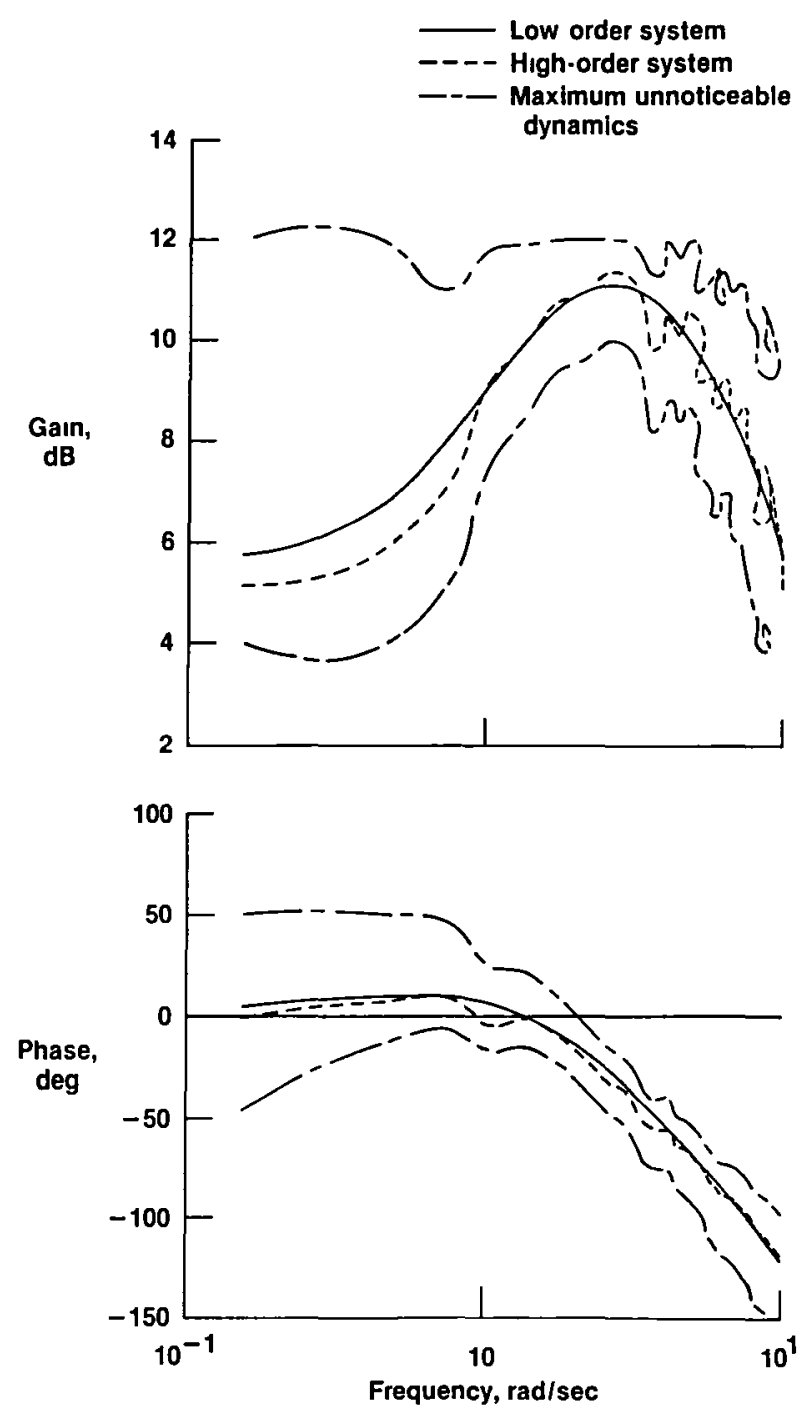

Fig. 13 Lower order equivalent system fit. 


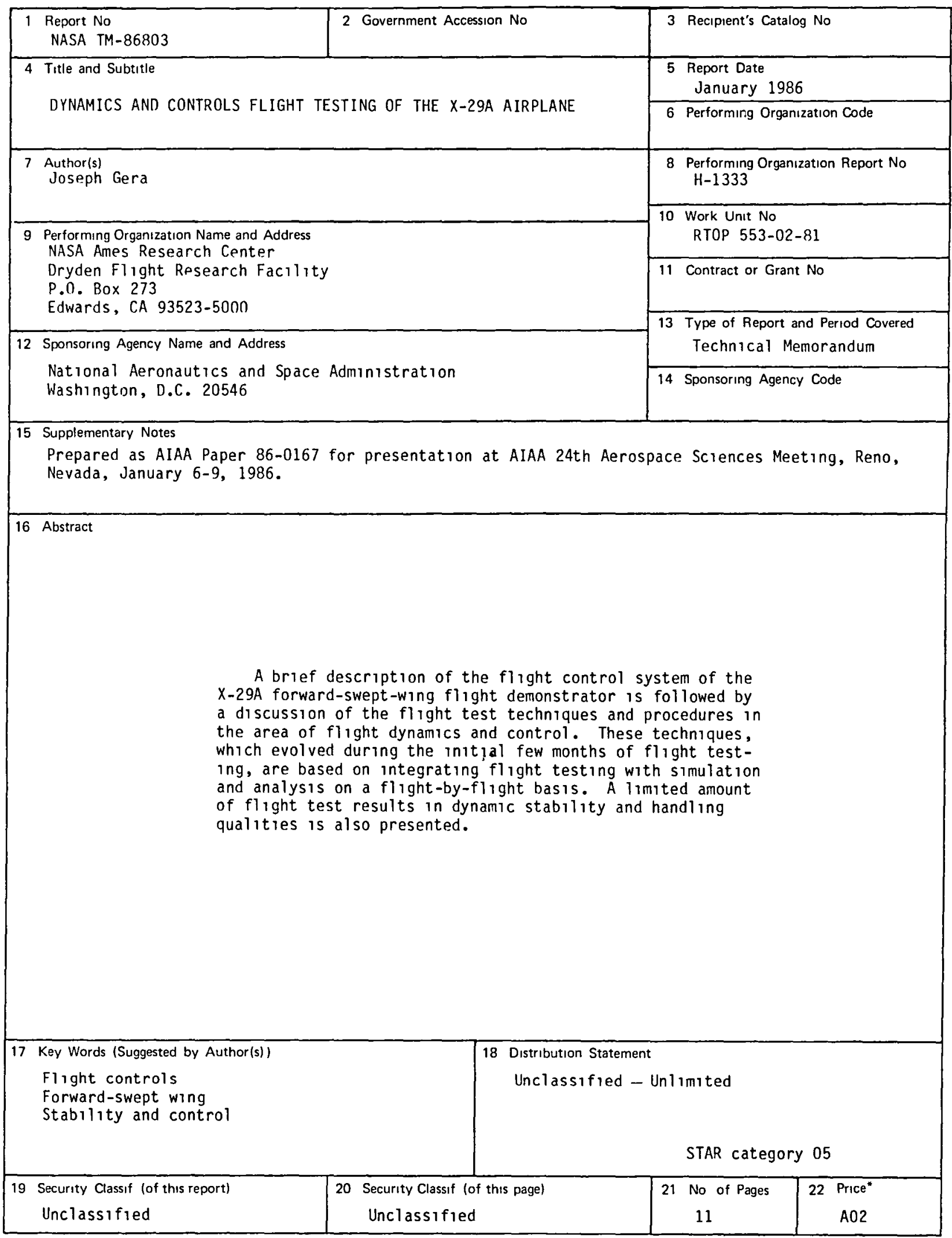

*For sale by the Natronal Technical Information Service, Springfield, Virginia 22161. 
End of Document 